\title{
A Study on Image Translation in Wang Wei's Landscape Poems Based on Three-dimensional Transformation in Eco-translatology
}

\author{
Feifei Chen ${ }^{1, *}$ \\ ${ }^{1}$ Department of College English, Zhejiang Yuexiu University, Shaoxing, China \\ *Correspondence: No.2801, Qunxian Middle Road, Shaoxing, China. Tel: 86-139-5756-7140. E-mail: \\ Chenfeifei0829@163.com
}

Received: August 17, $2020 \quad$ Accepted: October 13, 2020 Online Published: January 10, 2021

doi:10.5430/wjss.v8n1p12 URL: https://doi.org/10.5430/wjss.v8n1p12

\begin{abstract}
Ancient Chinese poetry has long been a hot topic in academic world. Recognized worldwide as a versatile literator in Tang Dynasty in China, Wang Wei composed a large quantity of excellent landscape poems containing rich images that can enrich the cultural connotation and create more artistic effect. Undoubtedly, the English translation of Wang Wei's landscape poems plays a pivotal role in letting Chinese culture goes global. In view of the large discrepancy of cultural traits between China and western countries, translators who are not familiar with the two cultures will be prone to run into setbacks and difficulties during the whole translating process. Accordingly, if translators misinterpret the images in poetry translation, readers may feel confused and thus fail to appreciate the authentic beauty. Therefore, the image translation in Wang Wei's landscape poetry is also of great significance. However, up to now, the academic world hasn't attached great importance to the theoretical value of images in translating ancient Chinese poetry and translating strategies targeting at ancient Chinese poems are still mainly hovering on the controversy between foreignization and domestication, neglecting other significant perspectives. Guided by the translation principle-the three-dimensional transformation in the theory of Eco-translatology, this study is expected to explore the feasibility of this translation method in the study of Wang Wei's poetry translation and to evaluate the quality of different versions of image translation from the linguistic, cultural, and communicative dimensions, aiming to offer both a guideline and a criterion for Wang Wei's poetry translation, to broaden the research ideas of literary translation as well as to help promote the lasting charm of the oriental culture to the world.
\end{abstract}

Keywords: Wang Wei's landscape poems, image translation, three-dimensional transformation, eco-translatology

\section{Introduction}

Ancient Chinese poetry, hailed as the magnificent legacy in classical Chinese literature featuring high artistic and aesthetic value, embodies Chinese people's eternal pursuit for wisdom and beauty. Among a sea of talented literati in ancient China, Wang Wei (701-761), one of the most influential figures of the Landscape Poetry School in the prime of the Tang Dynasty, composed more than four hundred excellent poems that have been passed down through the ages. Those beautiful poems, mainly depicting the natural landscapes and picturesque countryside with refreshing words and expressions to present a distinct and impressive aesthetic conception, manifest complete freedom from vulgarity and complexity. As Warner (2005) states, Wang Wei, one of the masters, is definitely referred to when talking about Chinese landscape poetry.

In more than one thousand and two hundred years, Wang Wei's poems have traveled across the ocean and have been translated into English, Spanish, French and many other versions, casting a far-reaching influence on the world literature. Undoubtedly, Wang Wei excels at capturing the keen sense of objects, using concise and vivid words to create visual and auditory images in nature, such as clouds, mountains, birds, sunsets, and moons to present the beauty of leisure, simplicity, freedom, and naturalness. American readers also show a preference for Wang Wei's poems for the poetic conception and Zen connotations embodied in his poems are in line with the cultural trend advocated by the American Imagist Poetry Movement. It is widely believed that Chinese poetry and poetics cast huge influence on modern American poetry and gave rise to the birth of Ezra Pound's imagist poems since the Taoist aesthetics in 
particular greatly enlightened and promoted the Western thoughts (Yip \& Feng, 2005). As Hinton (2019, p.31) put, "poetry is the cosmos awakened to itself." Wang Wei's landscape poetry, fusing outer nature and inner mind in a brilliant way, gives expression to the artistic and aesthetic tastes and concepts of the Chinese nation. Therefore, the English translation of Wang Wei's poems can be an important avenue to convey the amazing charm of classic Chinese culture to the western world and to enrich the world culture.

However, taking a sweeping view of domestic and foreign studies in this field, a lot of influential scholars have translated Wang Wei's poems, but in general, scholars conducted relatively few studies on the English translation of his poems. Furthermore, most of the previous studies have been carried out from the perspectives of linguistics and aesthetics, ignoring research from other related fields. Lastly, though the previous studies involve image translation in varying degrees, the research perspectives on them seem neither comprehensive nor microscopic. In the contemporary world, translating the exquisite poems of Wang Wei is still of great value in knowing the history because only through translation can modern people benefit from the wisdom of the past (Steiner, 2001, p.259). Therefore, based on a holistic, multidimensional, humanistic and dynamic perspective, this study, by taking the two masterpieces of Wang Wei's landscape poetry “The Cottage In Bamboo" (《竹里馆》) and “Deer Enclosure（《鹿柴》) ” as the research objects, adopts the three-dimensional transformation of Eco-translatology to explore the feasibility of this translation method in the study of Wang Wei's poetry translation and to evaluate the quality of different versions of image translation from the linguistic, cultural, and communicative dimensions, aiming to improve both theoretical and practical studies on Wang Wei's poetry translation, broaden the research ideas of literary translation as well as help promote the lasting charm of the oriental culture to the world.

\section{Literature Review}

\subsection{On Translation of Wang Wei's Poetry}

Wang Wei's verses, novel in theme, sincere in feeling and profound in artistic conception, demonstrate perfectly the intense aesthetic value and unique charm that have long attracted the attention from both domestic and foreign scholars. As the most prestigious Chinese translator in the field of English translation of ancient poetry, Xu (2016) made impressive contribution to Wang Wei's poetry translation by adopting the approach of "similarity in spirit" to match the "beauty in meaning" of Wang Wei's poetic style. Weng (1985) also translated several Wang Wei's masterpieces, including The Dale of Singing Birds ( 《鸟鸣涧》) in his book. As for foreign translators, Bynner (1929), who published fifteen translations of Wang Wei's poems, is regarded as the first one to introduce Wang Wei in the United States. In 1981, the American scholar Owen (1981) took one chapter to discuss Wang Wei's poems, using "austere simplicity" to characterize Wang Wei's poetic style. Regarded as an important representative of the Imagism in America, Pound was deeply influenced by Wang Wei's poetic style and was thought to equate Wang Wei's Taoism and Zen-Buddhism with his imagism and vorticism (Qian, 1993). Besides, other overseas scholars such as Hinton, Robinson, Fletcher, Burton Watson all have translated a certain number of Wang Wei's poems with their own unique styles, doing their utmost to enable foreign readers to savor the artistic beauty of these splendid literary works.

In terms of the comparative study of Wang Wei's poetry translation, scholars mostly focused on selecting representative works such as “An Autumn Evening in the Mountains" ( 《山居秋暝》) , "The Cottage In Bamboo" (《竹里馆》), “Deer Enclosure (《鹿柴》)”, etc., to carry out in-depth research on analyzing the translation strategies and styles of different translators from various perspectives. One of the notable studies conducted by Weinberger (1987) gave out the detailed analysis and critical commentary on the nineteen versions of "Deer Enclosure (《鹿柴》)" by poets and scholars from W. J. B. Fletcher to Gary Snyder, aiming to effectively convey the semantic meaning, cultural connotation and literary features of Wang Wei's works to foreign readers. Wade (2015) asked graduate students to practice the translation of Wang Wei's “Deer Enclosure (《鹿柴》) " and offered a close scrutiny on their versions. Cheng and Liu (2019) compares the similarities and differences between the two influential idyllic posts William Wordsworth and Wang Wei from a view of nature. The substantial studies conducted provide deeper insights into this domain.

In addition, researchers also look into Wang Wei's poetry translation with interdisciplinary perspectives. To be precise, manuscripts and documents made from the perspective of linguistics are in the largest quantity, then the number of studies based on hermeneutics, aesthetics, stylistics and other interdisciplinary concepts are also increasing. According to the results of the empirical research on the translation of Wang Wei's poems from the perspective of Reception Aesthetics, the translation in prosy form enjoyed higher popularity than that in rhymed form (Xu, 2012). Another case in point is made by Cao (2006) who, by adopting Relevance Theory, analyzed the classic work "The Dale of Singing Birds"(《鸟鸣润》) from the aspects of rhyme scheme, diction and ideorealm so as to achieve high translational validity. 
As a translator who had earned wide acclaim for translating classical Chinese poetry, Hilton (2007) collected poems from 5th- through 13th-century composed by the famous poets Li Po, Tu Fu and Wang Wei and rested eyes on the "rivers-and-mountains" poetry, attempting to fascinate not just readers who love poetry, but also the large community of readers who are interested in environmental awareness.

In general, those multifaceted studies have yielded considerable achievements and have enabled scholars and readers to grasp a deeper understanding of Wang Wei's style and spirit, but the depth of research areas still needs to be further explored.

\subsection{On Eco-translatology}

In 1987, Verschueren (1987), the secretary-general of the International Pragmatics Society put forward that ecology could be applied into the studies of language research and defined the linguistic adaptation as the adaptation of the language to the concrete environment, or the environment to the language, or both. Nourished from his concept, Professor Hu (2004) proposed the domestic approach to translation as adaptation and selection by originally incorporating Darwin's theory of evolution into translation studies and established a more comprehensive and systematic theoretical basis from ecological context. However, the term "eco-translatology" was formally formed in 2006 when $\mathrm{Hu}$ introduced it in the international conference "Translation of Global Culture: Towards an Interdisciplinary Theoretical Construction". Having done some researches under the framework of Eco-translatology, the well-known scholars such as Li \& Huang (2005), Wang (2001) and Cronin (2003) all thought highly of the localized theory combining Chinese and Western elements and attached great importance to its far-reaching influence on translation studies.

Studies in this area at home and abroad can be mainly divided into theoretical and practical categories based on the regime of the studies. With regard to theoretical studies, some scholars attempt to make deep investigations at the core concepts of Eco-translatology, such as translational eco-environment, translation principles, translation methods, translation process, etc., in order to improve its theoretical system from a holistic perspective. Cai (2006) believed that the theory that blended Darwin's doctrines of survival of the fittest into translation studies belonged to the post-modern theory which pursued the harmonious state of human beings and cultural context. Dollerup (2010) held that Eco-translatology was the first translation theory with truly originality that grew out of the European context since "its basis is in ancient Chinese thinking, its emphasis is on the harmony between man and his environments, and the relevance of collective vs. individual efforts are highlighted."

Since its emergence, Eco-translatology has received much attention both from home and abroad (Yu, 2016). This well-structured theory, especially its translation method, the three-dimensional transformation, is explanatory and operable for translation practices in various kinds of texts involving literary works, foreign publicity texts, tourism texts, commercial texts and public signs. To sum up, it is believed widely that the three-dimensional transformation can act as a solid theoretical criterion in providing a new perspective for translation criticism. Jiang (2009) commented on the three versions of “The Peony Pavilion”(《生丹亭》) translated by Cyril Birch, Wang Rongpei and Zhang Guangqian based on the three-dimensional transformation and drew the conclusion that translators all made more or less efforts in adapting to the linguistic and cultural dimensions in the translational eco-environment of the original text.

All in all, this interdisciplinary theory is getting increasing attention from scholars and experts worldwide, which indicates to a certain extent its international development tendency in the future.

\section{Theoretical Basis- The Three-dimensional Transformation in Eco-translatology}

There are a lot of theories with regard to the translation of ancient Chinese poetry, such as the "Three-Beauty" theory created by Xu (1979) and "Energy in Language" of Pond's theory of poetic translation (1968). All these have given out clear and effective guidelines for the poetry translation practices. Certainly, though each theory is identified with some sort of defects, it is almost impossible to establish an impeccable translation theory for the tough task. However, it is noteworthy that the domestic translation theory- Eco-translatology can be used as a sound theoretical basis for instructing and evaluating the translation of poetry. It clarifies a translation method centering on translators who are in the intimate relationship with the original work and writers and gives out new description and explanation on the essence, process, standards, principle and methodology of translation from ecological paradigm. The notion that translators should be given a certain amount of freedom in translation activities presents the core concept of a new human-oriented ontology, which can set translators free and gives them free rein to imagine, associate and translate. But at the same time, translators are also restricted by the elements beyond the texts, that is, they must adapt to the translational eco-environment of both source and target contexts. 
The idea "translation means ecological balance" in Eco-translatology is to inspect translation activities with the concept of "upholding the balance of the whole", which itself implies the integrity and harmony of translation and goes beyond the monotonicity of traditional paradigms ( $\mathrm{Hu}, 2019)$. Eco-translatology focuses on the overall effect created during translation process so that its multi-dimensional translation principle requires the translators to implement "three-dimensional transformation" on the premise of translators' good grasp of the cultural eco-system both in source language and the target language.

Having always been a frequently-discussed topic in the research field, the three-dimensional transformation denotes the proper adaptive selection and selective adaption of the three dimensions of language, culture, and communication in translation process following the philosophy of harmonization and unification. Since the three elements, namely, language, culture, and communication are closely intertwined and inseparable, when addressing the transformation of a certain dimension, we don't mean the "absence" of other dimensions. On the contrary, they are playing their parts simultaneously by interacting with each other, presenting a dynamic and balanced state.

\subsection{Transformation of Linguistic Dimension}

The transformation of linguistic dimension means that the translator needs to pay close attention to the adaptive transformation of the linguistic form, including vocabulary, syntax, rhetoric, phonetics, grammar and stylistic style in the original text when translating. Similarities can be found in each language regardless of nations and races. Although English and Chinese belong to different language families, it is still feasible to exchange the cultural information hidden in the texts between these two languages. Therefore, translators must at first comprehend the language forms in the original work in order to choose a suitable translation style and then make certain changes on the translated texts to faithfully convey the original meaning so as to approach to the ecological environment in source language. Only when translators truly see the differences in language structure, form, and cultural connotation and master the specific translation skills, can they successfully achieve the ultimate aim of language transplantation.

\subsection{Transformation of Cultural Dimension}

The transformation of cultural dimension requires translators to give priority to the effective transference of bilingual cultural connotation in the translation process. Language, as an integral part of culture, is acting as an indispensable carrier of culture while in turn, culture can only be presented through language. Generally, it is claimed that only with the expression of language can culture be interpretative and communicative.

Cultural generality renders the communication between different nations possible, while cultural individuality becomes the obstacle in the process of cultural exchanges. However, it has to be noticed that everyone has unique cognitive system to perceive the complicated cultural connotation, even people from one origin may have quite different understandings towards the same words or sentences. Indeed, without the same or similar cultural backgrounds, it's almost impossible to translate one word into another language by maintaining the absolute loyalty, let alone to touch readers' hearts. In fact, total equivalence of meaning cannot be achieved easily in translating literary works. As Nida (1969, p.109) put, "In any translation, there will be type of loss of semantic content, but the process should be so designed as to keep this to a minimum". Since the basic principle in literary translation is to keep the cultural fidelity to a maximum, translators are actually required to be quite familiar with two different cultures, keeping as close as possible to the cultural conventions and customs of the target language to truly realize the effective transference of textual meaning in the cultural dimension and to achieve the balance of the translational eco-environment.

\subsection{Transformation of Communicative Dimension}

Successful transformation of communicative dimension lies in transmitting communicative messages in bilingual environment in the translation process to the maximum extent. In a sense, translation equals communication in some aspects (Nida, 2001). There is no doubt that the communicative function of translation is an important means in cross-cultural communication. With limited knowledge of the target culture may "cause confusion, misunderstanding or even offense during communication process" (Köksal \& Yürük, 2020). As culturally-loaded words are often used in literary translation, translators may prone to misinterpret them sometimes which may cause great trouble for readers to fit in the ecological environment presented by the target language.

Therefore, in addition to adapting to the linguistic and cultural dimensions, translators should keep cultural consciousness in mind and remember that translation is actually a communicative process that transcends cultures and languages. That is to say, translators need to cater to the cognitive ability, reading habits and aesthetic taste of the target readers to ensure that they can understand the overall communicative intention, including explicit and implicit, conveyed by the original texts so as to achieve effective transformation of the communicative dimension. 


\section{Image Translation in Wang Wei's Landscape Poetry from Three-dimensional Transformation}

\subsection{Brief Introduction to Wang Wei and His Landscape Poetry}

Known as a prolific writer of poems on a wide variety of subjects, Wang Wei remains an influential literary figure even in the contemporary world. His unique aesthetic perception and outlook on life shown in his poetry are perfect reflection of the social culture in the prime of Tang Dynasty as well as of his transcendent personality and artistic accomplishments. However, his poems cannot be understood merely in historical context without incorporating his comprehension of the "interrelation of nature, enlightenment and art" (Williams, 2017).

The seclusive life provided endless inspiration for his poetry creation and endowed his landscape poems with a lofty implications and abundant aesthetic value. As Su Shi once put, "there is painting in his poetry, and poetry in his painting". Briefly, three levels of beauty can be detected in his landscape poetry. Let's look at the first level-the beauty in the poetic picture. Through the profound perception of natural scenery and artistic images, the poet made a perfect combination of color, light, shadow, sound and other elements to create a fresh and distant artistic realm. Representative works are “An Autumn Evening in the Mountains" (《山居秋暝》) and “Recent Clearing: An Evening View” (《新晴野望》). Furthermore, the beauty of the rhythm in his poems also attract people's attention. Being good at incorporating the sound in the scene and hiding the sound in the image, Wang Wei intelligently draw support from the unique poetic style featuring natural grace and serenity to break through the limitations of time and space and to induce readers to listen attentively to the melodious sounds hidden in the serene scenery. Works such as "Deer Enclosure”(《鹿柴》), “The Dale of Singing Birds” (《鸟鸣润》) belong to this category. Also, being called as Poet Buddha, he blends perfectly the beauty of Zen in his works. Zen implications are delicately revealed by tranquility and simplicity in idyllic natural landscapes, which enable the readers to feel "the self-consciousness of a poet to the 'Without me' of the state" ( Wu \& Tang, 2017). His well-known Zen poems are "Visiting the Temple of Accumulated Fragrance” (《过香积寺》) and “Visiting Monk Xuan” (《谒璇上人》).

\subsection{Images in Wang Wei's Landscape Poetry}

Image is viewed as the soul of poetry (Lafferty, 2012). Ancient Chinese poems are imbued with simple yet subtle images that may have more profound significance within our nation's cultural context (Yeh, 2000). Generally speaking, the combination of subjective feelings and objective scenery constitute "image" which semantically refers to an aesthetic concept.

Wang Wei's poems are composed of substantial images, such as the distant mountain, the flowing clouds, the tranquil forests and the clear moon that manifest the poet's detached disposition and deliver his love for pastoral life. With his keen sense, he can easily capture the essence of natural objects by observing them in an intuitive way, and strike a responsive chord in the heart of the readers. In his brilliant writing, imagery is no longer the mere addition of single objects, but an organic combination integrated with his life experiences.

Wang Wei employs the image of "humanless mountain" in his poems to convey his Zen philosophy and construct a unique ideological Utopia. Apart from mountain, "cloud" is also an image that appears frequently to set off the height of the surrounding scenery or represent free disposition of a recluse or express the joy of living in rural seclusion. In some sense, poetry is made of plenty of images, so translating poems fundamentally equals translating the images. Therefore, it is believed that the appropriate interpretation of those culture-loaded images in Wang Wei's poems stay as an integral part of successful translation.

\subsection{Case Study}

As an outstanding master of “绝句” (jué jù) which is a poem of four lines, each containing five or seven characters, with a strict tonal pattern and rhyme scheme, Wang Wei makes good use of quiet scenes like water and mist to create the painting-in-poetry artistic state in his quatrains, which set his poems free and soul-searching and brimmed with broad themes and serene flavor. In the following part, some of his famous poems translated by the excellent Chinese translator $\mathrm{Xu}$ Yuanchong as well as foreign translators will be analyzed on the basis of three-dimensional transformation to explore whether the vivid images in these poems are transmitted effectively or not.

\subsubsection{Analysis of “鹿柴”(lù zhài)}

The poem 鹿柴 (lù zhài), one of the best works of Wang Wei, has been translated by a large number of excellent translators like Xu Yuanchong, Cheng Baoyi, Burton Watson, Kenneth Rexroth and Ezra Pound. It presents the mystery of Zen by depicting the quiet and empty scenery in the deep forest around the scenic spot lù zhài, contrasting the dynamic with the static. Deep philosophical thoughts and thought-provoking Zen are blended ingeniously in this poem in which the poet indulges in the beauty of nature wholeheartedly, away from the fetters of worldly affairs. 
Here are the two versions of the first and second lines “空山不见人，但闻人语响” (kōng shān bú jiàn rén ,dàn wén rén yŭ xiăng ) in the poem.

Version One:

I see no one in mountains deep

But hear a voice in the ravine.

(Tr. Xu Yuanchong, 2000, p.56)

Version Two:

Deep in the mountain wilderness

Where nobody ever comes

Only once in a great while

Something like the sound of a far off voice.

(Tr. Kenneth Rexroth, 1970, p.176)

Clearly, the best part of the poem lies in the organic integration of all energetic and static elements in the picturesque landscape created by the poet. The echo of a person's sound makes the untraversed valley much quieter and emptier. The person unknown who can hardly be found in the deep mountain seems to be integrated into a whole with the surroundings. Here, human's mental state mingles with the enchanting nature. The Chinese words “空” (kōng) and “山” (shān) are considered as the significant culture-loaded words frequently used in ancient Chinese poems which often symbolize the hermits' indifference to the mortal fame and wealth as well as the desire to live in seclusion. The first couplet “空山不见人” ( kōng shān bú jiàn rén) means that “I can’t see anyone in the spacious and silent mountains". “空山” ( kōng shān ) as the most important image in the poem, offers a sense of wide vision that can intensify the artistic flavor of the poem from a holistic perspective. Xu translated “空山” into "mountains deep". As illustrated in the dictionary, "mountain" literally means "a very high hill", the height and depth of the mountain suggest that only few people can travel here while the quantity and density of mountains can also highlight the emptiness and gloom of the environment. Therefore, Xu's translation that gives priority to the beauty in sense, sound and form conforms to the translational eco-environment in the original work. However, Rexroth's version "mountain wilderness" seems not acceptable here for the word "wilderness" means "a large area of land that has never been developed or farmed" which can only mislead western readers to associate the image with the desolate fields. Compared with the tranquility and peacefulness reflected in the poem, the word "wilderness" seems improperly used, not only in linguistic dimension, but also in cultural and communicative dimensions. Worse still, he even translated the “不见人” ( bú jiàn rén) in the second line into "Where nobody ever comes", which greatly differs from the original meaning. It is obvious that the translator made a subjective conjecture about the original meaning and failed to describe the image of the original poem objectively. Overall, Xu's version gives rise to the full play of the translator's subjective initiative in selecting and adapting to the ecological environment of the original text no matter in terms of remaining the cultural implication of the poem or in terms of reproducing the whole artistic conception.

\subsubsection{Analysis of “竹里馆” (zhú lǐ guăn)}

It is difficult to translate some special images that only appear in traditional Chinese culture, such as the ancient musical instruments. In Wang Wei's poems, we can find a lot of words related to such instruments that bearing authentic Chinese flavor. For example, “古琴” (gǔ qín) is adopted as an important image in his famous work “竹里馆” (zhú lǐ guăn). “古琴” also known as “玉琴”（yù qín） and “七弦琴”（qī xián qín）, is a traditional Chinese plucked stringed instrument which enjoys a long history of more than 3,000 years and contains rich and profound cultural connotation. Seen as one way of self-cultivation, playing the special stringed instrument instills those elegant literati feelings of intoxication and relief. In a word, the reason why “古琴” art can be so unique and highly respected by Chinese people, in addition to its excellent function, is that the intriguing music, in line with the characteristics of traditional Chinese culture, can foster good virtues of ancient people. Thus, playing the “古琴” has become an important approach to personality cultivation and spiritual sublimation for ancient literati.

This poem describes the enjoyable leisure of a poet living alone in a human-less forest. A perfect blend of human and scenery is also reflected in it. In the original lines “独坐幽筀里, 弹琴复长啸” (dú zuò yōu huáng lǐ, tán qín fù cháng xiào）, although the poet’s “独坐” (dú zuò ), “弹琴” (tán qín) and “长啸” (cháng xiào) are simple movements, they highlight the solitude and emptiness in poet's inner heart. Here “琴” stands out as a crucial cultural image, so the translation of it is of great importance to the comprehension of the poem. The two versions are as follows: 
Version One:

Sitting among bamboos alone,

I play my lute and croon carefree.

(Tr. Xu Yuanchong, 2014, p.14)

Version Two:

I sit alone in bamboo that hides me,

Plucking the harp and whistling long.

(Tr. Stephen Owen, 2004, p.95)

In Xu's version, “琴” was translated into "lute”, narrowly speaking, it mainly refers to a general term for the ancient musical instruments used in Europe from the Middle Ages to the Baroque period. Sadly, his translation seems rather vague in semantics and cannot accurately express the appearance and function unique to Chinese “古琴”. So, in this aspect, he violates the effective transformation of three-dimensions and as a result, it is easy to cause the missing of cultural information. Another foreign translator Stephen Owen is quite obsessed with Chinese classical literature, especially Tang poetry. In his eyes, Tang poems, which is thousands of years away, are particularly beautiful, and still has great aesthetic value to people in modern age. He translated “琴” into "harp", one of the oldest plucked instruments in the world, which owns rich cultural connotation and melodious tune that often fascinates the audiences. He believes that translating it into lute is a bit rough, and in order to convey the cultural connotation of ancient Chinese musical instruments, it is necessary to be creative in translation. "The '琴' is nothing like the lute which has become the conventional translation. I have chosen to translate the “琴' as 'harp' (Owen, 1996)." By translating it in this way, it is much easier for western readers to understand the connotation of Chinese musical instruments, and to arouse their interest in traditional Chinese culture. Therefore, his version, being more faithful to the original translational eco-environment, can be conducive to give full play to the imagination of western readers, and thus can add more beauty to the artistic state of the poem.

In general, culture and translation are intertwined, and the latter can "coordinate or communicate different cultural traditions while respecting differences" (Gao, et al., 2019). When pursuing cultural generality in translation, translators also need to take the cultural individuality into consideration and to remember that translation should be an equal talk between different cultures, not exclusively an activity to express the same content in another language from. No one can really grasp a language without comprehending the cultural connotation behind the words. Though translators' acceptance of target culture often affects the translating process and interferes with the translators' adaptation and selection by different degrees, translators need to adapt to the whole cultural system of the specific language and attach great importance to the effective transference of cultural connotation by attempting to eliminate the differences in cultural attributes between source and target texts.

\section{Conclusion}

As is known to the readers and scholars interested in ancient Chinese culture, our ancient Chinese poetry has stretched across millennia, unleashing enchanting glamour to the whole world. However, when translating the poetry into another language, the conflicts between language and culture have always been intense and inevitable. Chinese poetry that embodies the special thinking modes of Chinese nation and aesthetic value of traditional Chinese culture is also an intangible bridge connecting eastern and western worlds. As one of the most prevailing Chinese poets abroad, Wang Wei's poems, both remarkable in terms of semantic content and artistic style, has exerted far-reaching influence on later literature. Hence, the translation of his poetry deserves more attention in the future. Noticeably, images play a crucial role in constructing the aesthetic effects of his poetry. On the one hand, those images which are incorporated into the elements such as rhyme, form, wording, are the essential parts of our ancient treasure. On the other hand, they intensify the connotation and artistic conception of poems. Undoubtedly, the effective transference of images is an important step to savor the beauty of ancient poetry.

Based on the detailed evaluation of different versions in image translation of Wang Wei's representative works from the linguistic, cultural, and communicative dimensions by applying the three-dimensional transformation into the translation of Wang Wei's poetry, this study proves that this translation method from holistic perspective can give out a new explanation for ancient poetry translation and act as both a guideline and a criterion in literary translation, aiming at enabling more and more foreign readers to visualize the profoundness and subtlety of classical Chinese culture. However, the study is relatively based upon a small sample of poems due to the limitation of space, therefore, it is 
beyond the scope of the study to provide a panoramic view of the generality of the three-dimensional transformation in ancient Chinese poetry translation. It is suggested that the other conceptual constructs in Eco-translatology that may influence the quality of poetry translation should be explored further in future research.

\section{Acknowledgement}

The author is grateful to Research Institute for Foreign Languages and Cultures of Zhejiang Yuexiu University (A Study on the English Translation of Ancient Chinese Poems Based on the Ecological Wisdom of "Heaven and Man Are United as One"-Subject No. 2020WGYYWH06) for providing financial assistance to carry out this research work.

\section{References}

Bynner, W. (1929). The Jade Mountain. New York: Alfred A. Knopf.

Cai, X. L. (2006). A brief comment on an approach to translation as adaptation and selection. Chinese Science \& Technology Translators Journal, 19(1), 58-59.

Cao, Y. (2006). On relevance theory in the translation of Wang Wei's Chan Poetry. Hebei Normal University, Shijiazhuang.

Cheng, L. Y., \& Liu, X. (2019). Contemplations on man and nature - a comparative study of the view of nature between William Wordsworth and Wang Wei. Advances in Social Science, Education and Humanities Research, 415, 423-428. https://doi.org/10.2991/assehr.k.200312.076

Cronin, M. (2003). Translation and globalization. London, New York: Routledge.

Dollerup, C. (2010). Chinese Eco-translatology in translation theory context. First international conference on Eco-translatology held in Macau, 1-7.

Gao, P. P., Gao, S. L., \& Zhong, Z. B. (2019). Study on geo-culture and translation based on the Chinese geography of Qinling Mountains-Huaihe River Line. Advances in Social Science, Education and Humanities Research, 322, 492-494, https://doi.org/10.2991/iserss-19.2019.126

Hinton, D. (2007). Mountain home: the wilderness poetry of ancient China. London: Anvil Press Poetry Ltd.

Hinton, D. (2019). Awakened cosmos: the mind of classical Chinese poetry. Boston: Shambhala Publications Inc.

Hu, G. S. (2004). An approach to translation as adaptation and selection. Wuhan: Hubei Education Press.

Hu, G. S., (2019). The theoretical construction of "Eco-paradigm" in translation studies. Chinese Translators Journal, 7(4), 4-33+188.

Jiang, X. H. (2009). Translator's selective adaptation and adaptive choice: comment on the three English translations of "the Peony Pavilion". Shanghai Translator, 4, 11-15.

Köksal, O., \& Yürük, N. (2020). The role of translator in intercultural communication. International Journal of Curriculum and Instruction, 12(1), 327-338.

Lafferty, G. P. (2012). Images beyond imagination: the soul of poetry. UK: Authorhouse.

Li, Y. S., \& Huang, Z. L. (2005). A unique theoretical construction: reading Hu Gengshen's approach to translation as adaptation and selection. Foreign Language Education, 26(6), 95-96.

Mu, S. X. (2004). Intercultural communication: on the English translation of Chinese classical poetry. Hefei: University of Science and Technology of China Press.

Nida, E. (2001). Language and culture. Shanghai: Shanghai Foreign Language Education Press.

Nida, E., \& Charles, T. (1969). The theory and practice of translation, Leiden: E. J. Brill. https://doi.org/10.2307/411434

Owen, S. (1981). The great age of Chinese poetry: The High Tang. London: Yale University Press.

Owen, S. (1996). An anthology of Chinese literature-beginnings to 1911. New York \& London: W. W. Norton Company.

Owen, S. (2004). The great age of Chinese poetry. Shanghai: Sanlian Bookstore. 
Pound, E. (1968). Literary essays of Ezra Pound. New York: New Directions.

Qian, Z. M. (1993). Ezra Pound's encounter with Wang Wei: toward the "Ideogrammic Method" of the Cantos. Twentieth Century Literature, 39(3), 266-282. https://doi.org/10.2307/441687

Rexroth, K. (1970). One hundred more poems from the Chinese. New York: New Directions.

Steiner, G. (2001). After Babel: aspects of language and translation. Shanghai: Shanghai Foreign Language Education Press.

Verschueren, J. (1987). Pragmatics as a theory of linguistic adaptation. Antwerp: International Pragmatics Association.

Wade, S. (2016). Thirteen ways of looking at Wang Wei. Subtropics, 2, 174-178.

Wang, N. (2011). Ecological literature and Eco-translatology: deconstruction and construction. Chinese Translators Journal, 2, 10-15.

Warner, D. X. (2005). The two voices of Wangchuan Ji: poetic exchange between Wang Wei and Pei Di. Early Medieval China, 2, 57-72. https://doi.org/10.1179/152991005791330203

Weinberger, E. (1987). Nineteen ways of looking at Wang Wei: how a Chinese poem is translated. New York: Moyer Bell Limited.

Weng, X. L. (1985). An English translation of Chinese ancient poems. Beijing: Beijing Publishing House.

Williams, N. (2017). Quasi-phantasmal flowers: an aspect of Wang Wei's mahāyāna poetics. Chinese Literature: Essays, Articles, Reviews (CLEAR), 39, 27-53.

Wu, C. L., \& Tang, J. C. (2017). The "without me" in Wang Wei's landscape poems. Advances in Social Science, Education and Humanities Research, 121, 134-136, https://doi.org/10.2991/ichssr-17.2017.27

$\mathrm{Xu}$, Y. C. (2014). Selected poems of Wang Wei. Beijing: China Translation \& Publishing Corporation, Ltd.

$\mathrm{Xu}, \mathrm{Y}$. H. (2012). Empirical research on the translation of Wang Wei's poems from perspective of reception aesthetics. Southwest University of Science and Technology, Mianyang.

Xuan, Y. C. (2000). Three hundred poems of Tang Dynasty in Chinese and English. Beijing: China Translation \& Publishing Corporation.

Yeh, M. (2000). The Chinese poem: the visible and the invisible in Chinese poetry. Manoa, 12(1), 139-146. https://doi.org/10.1353/man.2000.0042

Yip, W., \& Feng, G. R. (2005). National originals of Chinese poetry, poetics and their influence on modern American poetry. Oriental Forum, 2, 1-14.

Yu, Z. L. (2016). Translation as adaptation and selection: a feminist case. Perspectives, 25(1), 49-65, https://doi.org/10.1080/0907676X.2016.1197955

\section{Copyrights}

Copyright for this article is retained by the author(s), with first publication rights granted to the journal.

This is an open-access article distributed under the terms and conditions of the Creative Commons Attribution license (http://creativecommons.org/licenses/by/4.0/). 